\title{
Numerical Analysis of Composite Bolted Joints using the Arlequin
}

\section{Method}

\section{BINQI CHEN ${ }^{1, a^{*}}$, MINGBO TONG ${ }^{1, b}$, YIDING WANG ${ }^{2, c}$ and FANGLI WANG ${ }^{1, d}$}

${ }^{1}$ College of Aerospace Engineering, Nanjing University of Aeronautics and Astronautics, Nanjing 210016, P.R. China

${ }^{2}$ Chengdu Aircraft Design and Research Institute, Chengdu 610091, P.R. China achenbinqi7@163.com, btongw@nuaa.edu.cn, wyding127@163.com, ${ }^{\mathrm{d}}$ wangfangli2010@163.com

Keywords: Arlequin, Bearing failure, composite bolted joints, Lagrange multipliers.

Abstract. This paper aims to implement the Arlequin method to simulate the bearing failure in composite bolted joints. Arlequin coupling elements are established by introducing Lagrange multipliers to couple the 3D coarse elements and 3D refined elements. Refined elements are meshed one element each ply the same as the conventional model. Failure criteria and progressive damage approach are verified by comparing the conventional FE model with the experimental force-displacement curves from the literature. Coarse elements only have one element in the thickness to present properties of homogenized laminates. From the numerical results, the Arlequin FE model shows great feasibility and flexibility to get close to the conventional model, as well as saves almost half computational consumption.

\section{Introduction}

Composite materials are increasingly applied in aircraft structures, while it inevitably encounters many composite joints problems. Mechanical joints provide the primary means for transferring load among components in the construction of aircraft structures. In order to reduce the aircraft structural weight and costly testing expenses and ensure the structural safety of the aircrafts, many institutions and scholars have launched amount of research on the composite bolted joints. A huge body of work on composite mechanical joints is completed by McCarthy[1-8]. Bearing failure is a local compressive failure mode attributable to contact and friction between the bolt and the composite laminates[9]. Despite the advancement of computer techniques and computer simulation, three-dimensional simulation of bolted joint damage is still time-consuming. This definitely hinders the analysis on bolted joint damage in complicated structure.

The Arlequin method is first proposed by Dhia et al[10]. In this method, different level of detail part can be considered and distributed according to various internal energy weights via the Lagrange Multipliers on the overlapping zone. In this work, an attempt is made to apply the Arlequin method into establishing the model of composite bolted joints considering local effects of the bearing failure for these structures. Three-dimension composite joint models are analyzed and the efficiency of modeling the bearing damage by Arlequin method is demonstrated.

\section{The Arlequin coupling}

According to the Arlequin framework[10], the structure is composed of two overlapping sub-domains $\Omega_{1}$ and $\Omega_{2}$ which are meshed into coarse-scale and fine-scale separately and the 
overlapping meshes in the overlap $S$ are supposed to be coupling elements.

We assume that no boundary loads are applied on the intersecting zone, the energy can be written:

$$
\begin{aligned}
& E_{i}=\frac{1}{2} \int_{\Omega_{i}} \alpha_{i} \boldsymbol{\sigma}\left(\boldsymbol{u}_{\boldsymbol{i}}\right): \varepsilon\left(\boldsymbol{u}_{\boldsymbol{i}}\right) d \Omega-\int_{\Omega_{i}} \beta_{i} \boldsymbol{f} \cdot \boldsymbol{u}_{i} d \Omega \\
& \left\{\begin{array}{l}
\sum \alpha_{i}=\sum \beta_{i}=1 \text { in } S \\
\alpha_{i}=\beta_{i}=1 \quad \text { in } \Omega_{i} \backslash S
\end{array}\right. \\
& C\left(\lambda, \boldsymbol{u}_{i}\right)=\int_{\Omega_{s} ! \Omega_{i}}\left(\lambda \cdot \boldsymbol{u}_{i}+l^{2} \varepsilon(\lambda): \varepsilon\left(\boldsymbol{u}_{i}\right)\right) d \Omega
\end{aligned}
$$

In Eqs.(1) and (2), $\alpha_{i}$ are weight functions for scaling the internal energy in each sub-domain and $\beta_{i}$ for the external work. To keep the structural integrity in the overlapped zone $S$, a Lagrange multipliers field $\lambda$ and a coupling operator $C\left(\lambda, \boldsymbol{u}_{i}\right)$ are applied to link the freedom degrees of each sub-domain in the superposition zone. $l$ is the scaling parameter representative of the characteristic length.

Based on the principle of virtual work, it can be obtained:

$$
\begin{aligned}
& \forall \delta \boldsymbol{u}_{i} \in \boldsymbol{W}_{\boldsymbol{i}} \quad \int_{\Omega_{i}} \alpha_{i} \sigma\left(\boldsymbol{u}_{i}\right): \varepsilon\left(\delta \boldsymbol{u}_{i}\right) d \Omega+C\left(\lambda, \delta \boldsymbol{u}_{i}\right)=\int_{\Omega_{i}} \beta_{i} f \cdot \delta \boldsymbol{u}_{i} d \Omega \\
& \forall \delta \lambda \in \boldsymbol{W}_{\lambda} \quad C\left(\delta \lambda, \boldsymbol{u}_{\boldsymbol{1}}-\boldsymbol{u}_{2}\right)=0
\end{aligned}
$$

Where $\boldsymbol{W}_{\boldsymbol{i}}$ and $\boldsymbol{W}_{\lambda}$ denote, respectively, the kinematically conforming finite element ranges. The discrete problem (4) (5) can be solved and expressed as:

$$
\left[\begin{array}{ccc}
K_{1} & 0 & C_{1}^{T} \\
0 & K_{2} & -C_{2}^{T} \\
C_{1} & -C_{2} & 0
\end{array}\right]\left\{\begin{array}{l}
U_{1} \\
U_{2} \\
\Lambda
\end{array}\right\}=\left\{\begin{array}{l}
F_{1} \\
F_{2} \\
0
\end{array}\right\}
$$

where

$$
\begin{aligned}
& \boldsymbol{K}_{i}=\alpha_{i} \int_{\Omega_{i}} \boldsymbol{B}_{i}^{T} \boldsymbol{D} \boldsymbol{B}_{i} d \Omega \\
& \boldsymbol{F}_{i}=\beta_{i} \int_{\Omega_{i}} \boldsymbol{N}_{i}^{T} f d \Omega \\
& \boldsymbol{C}_{i}=\int_{\Omega_{i}}\left(\boldsymbol{N}_{\lambda}^{T} \boldsymbol{N}_{i}+l^{2} \boldsymbol{B}_{\lambda}^{T} \boldsymbol{B}_{i}\right) d \Omega
\end{aligned}
$$

$\boldsymbol{K}_{i}$ and $\boldsymbol{F}_{i}$ denote the stiffness matrices and the external force vectors associated to the sub-domain. $\boldsymbol{C}_{\boldsymbol{i}}$ and $\boldsymbol{U}_{\boldsymbol{i}}$ are the coupling matrices and the displacement vectors of each domain respectively. $\boldsymbol{\Lambda}$ is the Lagrange multiplier vector in the coupling zone.

\section{Analysis model}

The single-bolt, single-lap composite joint shown in Fig.1 was tested by McCarthy et al[5]. The specimen was loaded a quasi-static tensile displacement to one end while another end held was fixed. The composite plates with a stacking sequence of $[45 / 0-45 / 90]_{5 \mathrm{~s}}$ for the experiment were manufactured from HTA/6376, a high-strength carbon fiber-epoxy material. The material properties are shown in Table 1. The joints were assembled by an aerospace-grade titanium alloy bolt which was applied $16 \mathrm{Nm}$ pre-tightening force to provide a high degree of lateral constraint. 


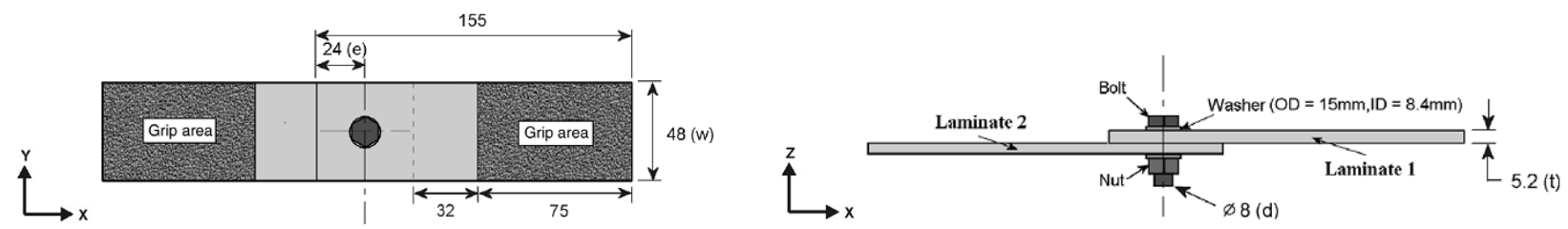

Fig.1 Single-lap joint specimen geometry

Table 1 Material properties

\begin{tabular}{|c|c|c|c|c|c|c|c|c|c|}
\hline \multirow{2}{*}{$\begin{array}{l}\text { Unidirectional properties } \\
\text { for HTA/ } 6376\end{array}$} & $\begin{array}{c}E_{11} \\
(\mathrm{GPa})\end{array}$ & $\begin{array}{c}E_{22} \\
(\mathrm{GPa})\end{array}$ & $\begin{array}{c}E_{33} \\
(\mathrm{GPa})\end{array}$ & $\begin{array}{c}G_{12} \\
(\mathrm{GPa})\end{array}$ & $\begin{array}{c}G_{13} \\
(\mathrm{GPa})\end{array}$ & $\begin{array}{c}G_{23} \\
(\mathrm{GPa})\end{array}$ & $v_{12}$ & $v_{13}$ & $v_{23}$ \\
\hline & 140 & 10 & 10 & 5.2 & 5.2 & 3.9 & 0. & 0.3 & 0.3 \\
\hline \multirow{2}{*}{$\begin{array}{l}\text { Homogenised laminate } \\
\text { properties for } \\
\text { quasi-isotropic lay-up }\end{array}$} & $\begin{array}{c}E_{x x} \\
(\mathrm{GPa})\end{array}$ & $\begin{array}{c}E_{y y} \\
(\mathrm{GPa})\end{array}$ & $\begin{array}{c}E_{z z} \\
(\mathrm{GPa})\end{array}$ & $\begin{array}{c}G_{x y} \\
(\mathrm{GPa})\end{array}$ & $\begin{array}{c}G_{x z} \\
(\mathrm{GPa})\end{array}$ & $\begin{array}{c}G_{y z} \\
(\mathrm{GPa})\end{array}$ & $v_{x y}$ & $v_{x z}$ & $v_{y z}$ \\
\hline & 54.25 & 54.25 & 12.59 & 20.72 & 4.55 & 4.55 & 0.309 & 0.332 & 0.332 \\
\hline
\end{tabular}

In order to assess the application of Arlequin method in the bolted joints, two different Finite elements models are established. Fig. 2 shows the conventional FE model using one solid element per ply in the thickness direction. Fig. 3 is the FE model coupling coarse finite elements in the section B with the refined elements in the section A. Dual mesh is overlapped between the two yellow dashed region. It is observed that one coupling element is combined with one coarse element and many fine elements. While the fine elements are meshed one solid element per ply like the conventional FE meshes, the coarse elements are assigned only one solid element in the thickness and the homogenised laminate properties is shown in Table 1. To make a comparison, the same failure criterion and progressive failure method are chosen to ensure consistency applied in the conventional model and Arlequin model.

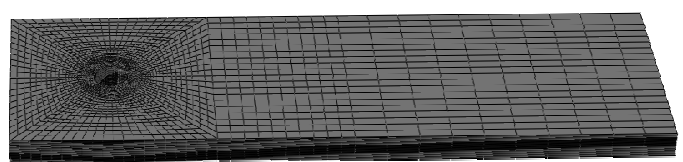

Fig.2 Conventional FE model

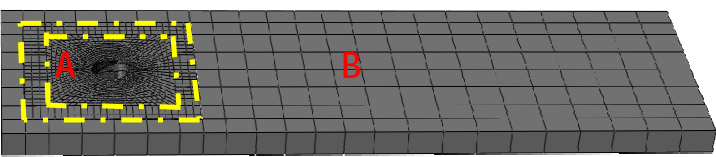

Fig.3 FE model using Arlequin coupling

\section{Results and discussion}

A comparison between the experimental and FE analysis results is shown in Fig.4. It can be noted that the force-displacement curves of FE-analysis match the experimental bearing test [5] regardless of the linear segment or the progressive damage segment generally, and also the peak loads are coincident with the experimental results. The rationality of failure criterion and progressive failure method is approved by comparing with the test.

It also can be seen that the force-displacement results for Arlequin model and Conventional model agree with each other. Yet there is a distinct difference, it is considered that different self-adaptive load-step sizes in ABAQUS and error of element coupling matrix using the Arlequin method induce this phenomenon. Basically, the initial damage of two models happens in the same position and are caused identically by the matrix tensile failure. From the comparison of the five failure states under the maximum bearing load as shown in Table 2, Arlequin model is consistent with conventional model. These results demonstrate application of the Arlequin method in analysis of bolted bearing failure of composite joints could not affect the damage mechanism and damage process, and can obtain the similar results as the conventional model.

Four aspects are assessed for comparing the efficiency between these two FE models. As 
shown in Table 3, while the number of elements in Arlequin model decrease $34.5 \%$, the computer memory usage is reduced from $27.4 \mathrm{~GB}$ to $17.8 \mathrm{~GB}$ compared with conventional model. However, the most powerful comparisons are the reduction of CPU times and wallclock times, the times consumption is cut approximately 46\%. High efficiency shows in Arlequin model under the analysis of bearing failure. Based on the above, one can draw a conclusion that analyzing bearing failure in composite bolted joints using the Arlequin framework can consume less computer resources while still guaranteeing the accuracy.

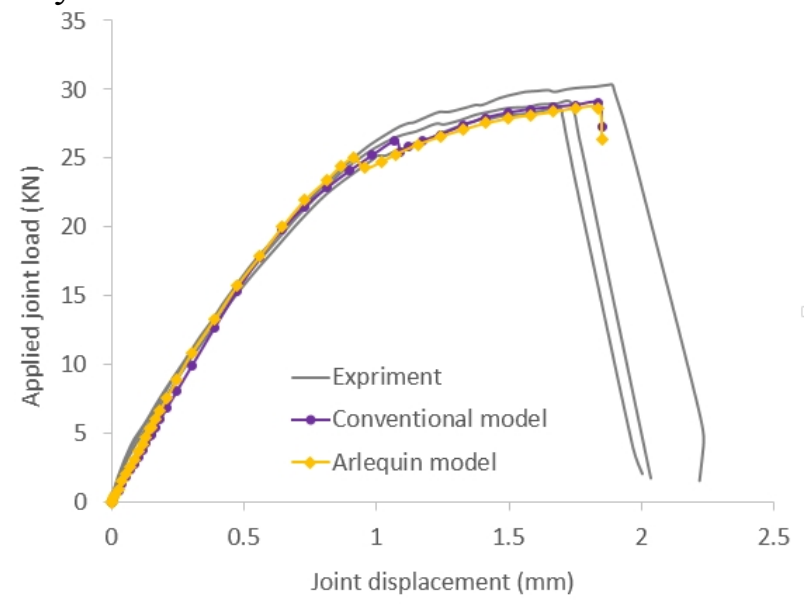

Fig.4 Force-displacement curve

Table 2 Bearing failure

\begin{tabular}{|c|c|c|c|c|c|c|}
\hline & $\begin{array}{l}\text { Initial } \\
\text { damage } \\
\text { (Matrix } \\
\text { tensile } \\
\text { failure) }\end{array}$ & $\begin{array}{c}\text { Fiber } \\
\text { compression } \\
\text { fracture } \\
\text { under } \\
\text { maximum } \\
\text { load }\end{array}$ & $\begin{array}{l}\text { Fiber tensile } \\
\text { fracture } \\
\text { under } \\
\text { maximum } \\
\text { load }\end{array}$ & $\begin{array}{c}\text { Matrix } \\
\text { compression } \\
\text { fracture } \\
\text { under } \\
\text { maximum } \\
\text { load }\end{array}$ & $\begin{array}{l}\text { Matrix } \\
\text { tensile } \\
\text { fracture } \\
\text { under } \\
\text { maximum } \\
\text { load }\end{array}$ & $\begin{array}{l}\text { In-plane she } \\
\text { ar damage } \\
\text { under } \\
\text { maximum } \\
\text { load }\end{array}$ \\
\hline \multicolumn{7}{|l|}{$\begin{array}{l}\text { Conventio } \\
\text { nal model }\end{array}$} \\
\hline & the nominim & (inim & Whatmonsm & Swm & Tratur & Vulumpros \\
\hline \multicolumn{7}{|l|}{$\begin{array}{c}\text { Arlequin } \\
\text { model }\end{array}$} \\
\hline & $=$ & $\operatorname{men}$ & $\equiv$ & Nate & 를 & 雎 \\
\hline
\end{tabular}

Table 3 Comparison of efficiency between conventional model and Arlequin model

\begin{tabular}{cccc}
\hline & Conventional model & Arelquin model & percentage reduction \\
\hline Number of elements & 231,520 & 151,536 & $34.5 \%$ \\
Memory usage(GB) & 27.4 & 17.8 & $35 \%$ \\
Total CPU times (min.) & 5,079 & 2,727 & $46.3 \%$ \\
Wallclock times(min.) & 658 & 352 & $46.5 \%$ \\
\hline
\end{tabular}

\section{Conclusions}

In this paper, the Arlequin method is developed to simulate the bearing damage of 3D-3D coupled composite bolted joints. The Arlequin coupling elements are established in ABAQUS. 
Conventional FE model is used to verify the failure criteria and progress failure approach by comparison with the experimental bearing test results under the entire load history. Then the Arlequin model using the same criteria and approach compares with the conventional to illustrate its effectiveness. The Arlequin model presents good agreement with the conventional model such as load-displacement curve and damage states, and also can enhance the calculation efficiency greatly.

This work attempts to indicate a promising path to analyze the composite mechanical joints considering with the bearing progressive failure in the complex structures. By application of the Arlequin method, only the important region needs the refined meshes, while the other can be simplified and connected with the refined region by this coupling method.

\section{Acknowledgments}

This work is supported by the National Natural Science Foundation of China (No. 11302105) and Aeronautical Science Foundation of China (No. 2014ZF52074).

\section{References}

[1] McCarthy, M.A., Lawlor, V.P., Stanley, W.F., et al.: Bolt-hole clearance effects and strength criteria in single-bolt, single-lap, composite bolted joints. Composite Science and Technology 62, 1415-1431 (2002)

[2] McCarthy, M.A., McCarthy, C.T.: Finite element analysis of the effects of clearance on single-shear, composite bolted joints. Journal of Plastic, Rubber and Composites 32 (2003)

[3] McCarthy, M.A., McCarthy, C.T., Lawlor, V.P., et al.: Three-dimensional finite element analysis of single-bolt, single-lap composite bolted joints: Part I - model development and validation. Composite Structures 71, 140-158 (2005)

[4] McCarthy, C.T., McCarthy, M.A.: Three-dimensional finite element analysis of single-bolt, single-lap composite bolted joints: Part II - effects of bolt-hole clearance. Composite Structures 71, $159-175$ (2005)

[5] McCarthy, C.T., McCarthy, M.A., Stanley, W.F, et al.: Experiences with modeling friction in composite bolted joints. Journal of Composite Materials 39, 1881-1908 (2005)

[6] Egan, B., McCarthy, C.T., McCarthy, M.A., et al.: Modelling a single-bolt countersunk composite joint using implicit and explicit finite element analysis. Computational Materials Science 64, 203-208 (2012)

[7] Gray, P.J., O’Higgins, R.M., McCarthy, C.T.: Effect of thinkness and laminate taper on the stiffness, strength and secondary bending of single-lap, single-bolt countersunk composite joints. Composite Structures 107, 315-324 (2014)

[8] Egan, B., McCarthy, M.A., Frizzell, R.M., et al.: Modelling bearing failure in countersunk composite joints under quasi-static loading using 3D explicit finite element analysis. Composite Structures 108, 963-977 (2014)

[9] Xiao, Y., Wang, W., Takao, Y., Ishikawa, T.: The effective friction coefficient of a laminate composite, and analysis of pin-loaded plates. Journal of Composite Materials 34, 69-87 (2000)

[10] Dhia, H.B.: Multi-scale mechanical problems: the Arlequin method. C.R. Acad. Sci. II b 326, 899-904 (1998) 